\title{
Four-year trends in the treatment of cerebral aneurysms in Poland in 2009-2012
}

\author{
Tomasz Tykocki • Kacper Kostyra • Marcin Czyż • \\ Bogusław Kostkiewicz
}

Received: 23 October 2013 / Accepted: 18 January 2014 / Published online: 6 February 2014

(C) The Author(s) 2014. This article is published with open access at Springerlink.com

\begin{abstract}
Background The dilemma concerning the appropriate treatment of the intracranial aneurysms (IAs) has not yet been resolved and still remains under fierce debate. This study refers to the recent trends in the use of and outcomes related to coiling compared with clipping for unruptured and ruptured IAs in Poland over a 4-year period.

Methods The analysis refers to treatment of IAs performed in Poland between 2009-2012. Patients' records were crossmatched by ICD-9 codes for ruptured SAH (430) or unruptured cerebral aneurysm (437.3) along with codes for clipping (39.51) and coiling (39.79, 39.72, or 39.52). Multivariable logistic regression was used to compare in-hospital deaths, hospital length of stay (LOS), therapy allocation and aneurysm locations in unruptured vs. ruptured and clipped vs. coiled groups. Differences in the number of procedures between 16 administrative regions were standardized per 100,000 people.

Results In 2009-2012, 11,051 procedures were identified, including 5,968 ruptured and 5,083 unruptured aneurysms. Overall increase was $2.3 \%$ in clipping and $13.1 \%$ in coiling; a significant trend was found in endovascular procedures $(\mathrm{p}=$ 0.044). Ruptured aneurysms were clipped more frequently $(\mathrm{OR}=1.66 ;)$; in unruptured IAs, endovascular procedure was preferred 3.5 times more than clipping. The annual in-hospital
\end{abstract}

T. Tykocki $(\bowtie)$

Department of Neurosurgery, Institute of Psychiatry and Neurology,

Sobieskiego Street No 9, Warsaw 02-957, Poland

e-mail: ttomasz@mp.pl

K. Kostyra $\cdot$ B. Kostkiewicz

Department of Neurosurgery, Central Clinical Hospital Ministry of Interior in Warsaw, Warsaw, Poland

M. Czyż

Department of Neurosurgery, Wroclaw Medical University, Wroclaw, Poland mortality was $7.6 \%$ in clipping and $6.7 \%$ in endovascular treatment. LOS was two times longer after clipping in unruptured aneurysms $(\mathrm{OR}=2.013)$. After the procedures were standardized per 100,000 people, the average for Poland was established as 9.09 in 2009, 10.86 in 2010, 10.55 in 2011, and 11.49 in 2012. This index had the highest values in Mazovia (12.9, 2009; 15.4, 2010; 17.4, 2011; 18.6, 2012.

Conclusions Data analysis revealed an increase in overall number of IAs treated in Poland between 2009-2012. A significant upward trend of endovascular procedures was found, whereas the number of clipped aneurysms remained relatively steady over the study period.

Keywords Intracranial aneurysms $\cdot$ Clipping $\cdot$ Endovascular treatment $\cdot$ Trends

\section{Introduction}

The dilemma concerning the appropriate treatment of intracranial aneurysms (IAs) has not yet been resolved and still remains under fierce debate. The introduction of Guglielmi detachable coils in 1991 [9] initiated a new epoch in cerebrovascular therapy and opened the door for endovascular procedures in the management of IAs. Thus, the hegemony of surgical clipping was broken by aneurysm coiling causing shifting treatment paradigms. The number of endovascular procedures has grown steadily since 1990s [6, 10, 11, 14]. At the same time, the number of clipped IAs had a downward trend with a significant decrease in the group of unruptured aneurysms $[1,4,6,10]$. A marked change in the management of IAs in favour of coiling has been noticed since the publication of the International Subarachnoid Aneurysm Trial (ISAT) in 2002 [17]; additionally, the total number of any intervention, including both clipping and coiling, has also radically increased. Interestingly, the last report from the Barrow Study 
provided some new data on this intriguing issue. At 3-year follow-up, patients in the clip group reached a significantly higher degree of aneurysm obliteration and a significantly lower rate of recurrence and retreatment, but embolization showed a more favourable outcomes [23].

The excellent and sophisticated scientific descriptions and trend analysis in the treatment of IAs predominantly come from U.S. data and at the same time there is a lack of similar reports from other regions.

In this study, the authors present 4-year trends in the treatment of IAs in Poland. Data includes endovascular and neurosurgical interventions, ruptured and unruptured IAs and takes into account the differences between 16 administrative regions of Poland.

\section{Methods}

The present statistical analysis refers to IAs treated in Poland between 2009 and 2012. These procedures are grouped according to the system of diagnosis-related groups (DRG) (pol. Jednorodne Grupy Pacjentów, JGP), as proposed by the National Health Fund (pol. Narodowy Fundusz Zdrowia, NFZ). Data were obtained from the NFZ database and supplemented by the official correspondence with the NFZ.

Patients' records were cross-matched by ICD-9 codes for ruptured SAH (430) or unruptured cerebral aneurysm (437.3) along with procedure codes for aneurysmal clipping (39.51) and coiling (39.79, 39.72, or 39.52). Additionally, all aneurysms were subgrouped into either the anterior or posterior cerebral circulation location. In the first stage, the absolute numbers of procedures were estimated, followed by the comparison of results between unruptured vs. ruptured, clipped vs. coiled and posterior vs. anterior cerebral circulation aneurysms. Demographic characteristic for the Polish population and differences in the number of procedures between 16 administrative regions (voivodships) were standardized per 100,000 people. The population data was obtained from Statistical Yearbooks of the Central Statistical Office. The two main cohorts (unruptured and ruptured aneurysms) were compared against one another for two primary end points - in-hospital death and hospital length of stay (LOS). Secondarily, similar comparison in the main cohorts for three other features, unruptured vs. ruptured, clipped vs. coiled and posterior vs. anterior cerebral circulation aneurysms, were conducted. Patients with both a ruptured and unruptured aneurysm in one hospitalization were included in the ruptured group. We excluded patients who were listed with procedure codes for both clipping and coiling, and those who received diagnosis codes for both an unruptured aneurysm and SAH.
Statistical analysis

Multivariable logistic regression was used to calculate the odd ratios and $95 \%$ CIs for the comparison of endovascular treatment and surgical clipping for the in-hospital mortality, sex, length of stay and the anatomical origin of the aneurysms. We also calculated and tabulated category-level compound annual growth rates (CAGRs) for the whole analyzed period. Trends over time were modeled using simple linear regression and tested for significance with analysis of variance (ANOVA), assuming that the dependent variables are numbers of procedures and time points (years) are independent variables. Statistical significance was defined as a type I error $<0.05$.

\section{Results}

From 2009 to 2012, 11,051 procedures associated with the treatment of IAs were identified, including 5,968 ruptured and 5,083 unruptured aneurysms.

The mean age was $52.3 \pm 3.8$ years and there were 6,666 women $(60.3 \%)$. Five thousand one hundred and twenty-five (46.4\%) aneurysms were treated by neurosurgical clipping and 5,926 (53.6 \%) by endovascular procedures. The overall in-hospital mortality rate was $7.1 \%$ and the mean length of stay $9.3 \pm 0.9$ days. The location ratio of anterior to posterior circulation aneurysms was $6: 1(9,228: 1,545)$; the highest number of IAs was in the ICA 3,769 (34 \%) and ACA 3,199 $(29 \%)$ territory (Table 1$)$.

Comparison of the surgical clipping and endovascular treatment

An overall increase in the number of all IAs treated between 2009-2012 was observed, the CAGR was calculated as $6 \%$ for the entire period, but the change in volume was not significant by ANOVA $(p=0.112)$ (Table 2). An increase in the number of procedures for neurosurgical clipping by $2.3 \%$ and endovascular treatment by $13.1 \%$ was observed; however, a significant trend was found only in the endovascular group $(p=0.044)$. There has been a steady increase in the proportion of unruptured aneurysms including both procedures between 2008 and 2009 (CAGR, $18.2 \%$; $\mathrm{p}=0.036$ ); a similar increment was found for the endovascular group (CAGR, 22.1\%; $\mathrm{p}=0.023$ ), but not in the clipping one (Fig. 1). The overall number of clipped aneurysms remained relatively steady over the entire period, but the volume of unruptured aneurysms showed an upward trend (Fig. 2). Posterior circulation aneurysms have increased almost three times in the study period with a significant increment between 2009 and 2010; this tendency was associated with a remarkable change in the treatment choice of these IAs favouring 
Table 1 Comparison of the selected factors between clipping and endovascular groups

Pooled analysis for 2009-2012

LOS - length of stay

*odds ratio adjusted per year

\# territory of internal carotid artery (ICA); middle cerebral artery (MCA); anterior cerebral artery (ACA)

\begin{tabular}{|c|c|c|c|c|}
\hline & Endovascular $\mathrm{N}=5,926$ & Clipping $\mathrm{N}=5,125$ & Odds ratio* & CI $95 \%$ \\
\hline In-hospital mortality & $396(6,7 \%)$ & $391(7,6 \%)$ & 1.158 & 1.001 to 1.339 \\
\hline Age (years) & $54.9 \pm 4.3$ & $51.3 \pm 3.5$ & 0.910 & 0.867 to 1.012 \\
\hline No. of women & $3,827(64.6 \%)$ & $2,839(55.4 \%)$ & 0.685 & 0.634 to 0.739 \\
\hline LOS (days) & $6.6 \pm 0.8$ & $11.9 \pm 0.7$ & 2.049 & 1.274 to 3.296 \\
\hline Posterior circulation (n) & $1,205(20.3 \%)$ & $350(6.8 \%)$ & 0.294 & 0.260 to 0.334 \\
\hline $\operatorname{ICA}(\mathrm{n}) \#$ & $2,092(35.3 \%)$ & $1,675(32.7 \%)$ & 0.886 & 0.818 to 0.959 \\
\hline MCA (n) \# & $726(12.2 \%)$ & $1,534(29.9 \%)$ & 3.054 & 2.768 to 3.370 \\
\hline $\mathrm{ACA}(\mathrm{n}) \#$ & $1,903(32.1 \%)$ & $1,566(30.6 \%)$ & 0.922 & 0.850 to 0.999 \\
\hline
\end{tabular}

endovascular treatment. The multivariate pooled analysis for the entire study period adjusted per year showed that the average length of hospital stay was longer in endovascular treatment ( $\mathrm{OR}=2.049 ; 95 \%$ CI 1.274 to 3.296). Posterior circulation aneurysms were 3.4 times more likely to be coiled than clipped; the opposite relationship was found for MCA aneurysms being more frequently clipped than coiled (OR= $3.053 ; 95 \%$ CI 2.768 to 3.370 ). The annual in-hospital mortality was estimated as $7.6 \%$ in clipping and $6.7 \%$ in endovascular treatment; the difference did not reach statistical significance. Annual comparison between clipping and endovascular treatment was presented in Table 3.

The differences between these two groups were more pronounced when comparing ruptured and unruptured aneurysms (Fig. 3a, b). Ruptured aneurysms were clipped more frequently $(\mathrm{OR}=1.66 ; 95 \% \mathrm{CI} 1.552$ to 1.794$)$, and in the unruptured group endovascular procedure was preferred 3.5 times more than clipping. The length of hospital stay was almost equal after $\mathrm{SAH}$, whereas in unruptured aneurysms, the hospital stay was two times longer after clipping $(\mathrm{OR}=2.013 ; 95 \% \mathrm{CI} 1.814$ to 2.235$)$. Posterior circulation aneurysms were more likely to be coiled in both ruptured $(\mathrm{OR}=1.7 ; 95 \% \mathrm{CI} 1.45$ to 2.04$)$ and unruptured $(\mathrm{OR}=8.48 ; 95 \% \mathrm{CI} 6.62$ to 10.99$)$ groups. On the other hand, MCA aneurysms were allocated mostly for clipping $(\mathrm{OR}=3.19 ; 95 \% \mathrm{CI} 2.748$ to 3.703 in the $\mathrm{SAH}$ group; $\mathrm{OR}=3.612 ; 95 \% \mathrm{CI} 3.148$ to 4.146 in the non-SAH group).

Geographical variations in the treatment of cerebral aneurysms

In half of the 16 administrative regions, an increase in the number of clipped and coiled aneurysms over the study period was found (Table 4 ). The highest CAGR was $14 \%$ for clipped aneurysms over the study period in Greater Poland; the change was from 34 in 2009 to 58 in 2012. The greatest progression in endovascular treatment was found in the Lublin region with a CAGR of $33.3 \%$ (62 in 2009 to 196 in 2012). The cumulative number of procedures in the 4-year period was the highest in Mazoivia and reached 1,680 (average per year $-420 / 78.59$ ) in clipping and 1,710 (average per year 427.5/55.51) in endovascular treatment. There was a reduction in the number of clipped aneurysms in three regions between 2009-2012 (Lesser Poland -1 \%; Swietokrzyski Region - $11 \%$; Opole Region - $8 \%$ ). No endovascular treatment
Table 2 Number of aneurysm treatment procedures in Poland, 2009-2012

\footnotetext{
* $\mathrm{P}$ value is the result of ANOVA $\mathrm{F}$ test for significance of a linear trend over time
}

\begin{tabular}{|c|c|c|c|c|c|c|}
\hline & \multicolumn{4}{|c|}{ Calendar year } & \multirow[b]{2}{*}{$\mathrm{p}^{*}$} & \multirow{2}{*}{$\begin{array}{l}\text { Compound annual } \\
\text { growth rate }(\%) \\
2009-2012\end{array}$} \\
\hline & 2009 & 2010 & 2011 & 2012 & & \\
\hline Clipping + endovascular & 3,501 & 4,185 & 4,063 & 4,427 & 0.112 & $6.0 \%$ \\
\hline unruptured & 728 & 1,108 & 1,162 & 1,421 & 0.036 & $18.2 \%$ \\
\hline ruptured & 2,773 & 3,077 & 2,901 & 3,006 & 0.400 & $2.0 \%$ \\
\hline posterior circulation & 166 & 396 & 412 & 495 & 0.081 & $31.4 \%$ \\
\hline Clipping & 1,199 & 1,345 & 1,269 & 1,312 & 0.461 & $2.3 \%$ \\
\hline unruptured & 267 & 399 & 393 & 397 & 0.233 & $10.4 \%$ \\
\hline ruptured & 932 & 946 & 876 & 915 & 0.484 & $-0.5 \%$ \\
\hline posterior circulation & 53 & 53 & 79 & 79 & 0.104 & $10.4 \%$ \\
\hline Endovascular & 1,103 & 1,495 & 1,525 & 1,803 & 0.044 & $13.1 \%$ \\
\hline unruptured & 461 & 709 & 769 & 1,024 & 0.023 & $22.1 \%$ \\
\hline ruptured & 642 & 786 & 756 & 779 & 0.266 & $5.0 \%$ \\
\hline posterior circulation & 113 & 343 & 333 & 416 & 0.112 & $38.5 \%$ \\
\hline
\end{tabular}


Fig. 1 Column graph bar presenting number of procedures in 2009-2012 for ruptured and unruptured aneurysms

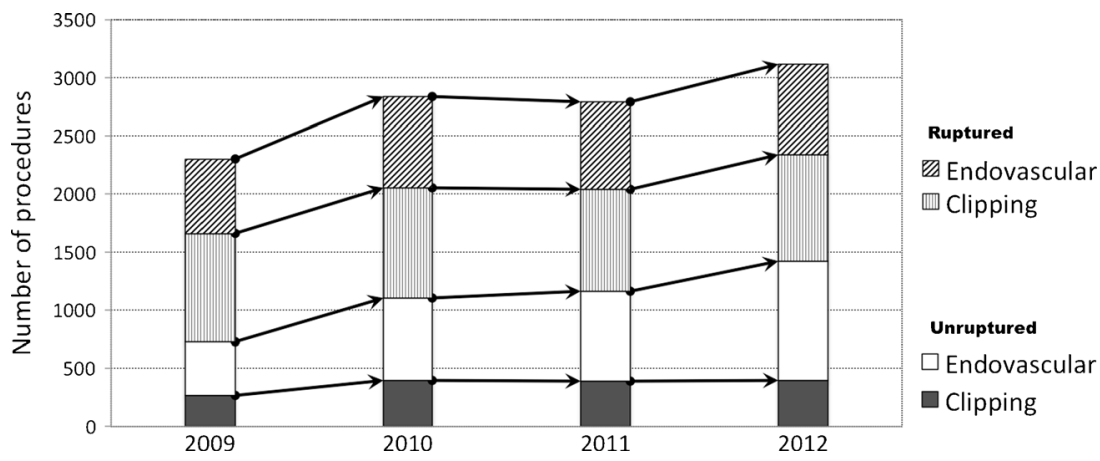

was found in one region (Lubusz Region) throughout the entire study period. In two regions there was a downward tendency in the number of endovascular procedures (Opole Region -6.9\%; Podlasie Region -8 \%).

After the procedures were standardized per 100,000 people, the average for Poland was established as 9.09 in 2009; 10.86 in 2010, 10.55 in 2011; 11.49 in 2012. This index had the highest values in Mazovia (12.9 in 2009; 15.4 in 2010; 17.4 in 2011; 18.6 in 2012) with CAGR of $10 \%$. In three other regions the index (procedures/100,000) was above the average for Poland (Greater Poland, Lublin Region, West Pomeranian) (Fig. 4).

\section{Discussion}

In this retrospective analysis, data from the Polish national database was used to investigate trends in aneurysm treatment patterns in Poland for the 4-year interval. A moderate increase in the overall number of aneurysms treatment, both by clipping or endovascular treatment, was noted over the study period. This increase is represented predominantly by unruptured and posterior circulation aneurysms with yearly increase by $18.2 \%$ and $31.4 \%$, respectively. For both ruptured and unruptured aneurysms, the trend was toward an increased use of endovascular procedures by $13.1 \%$ annually. The relative increase in coiling usage was greater in patients with no SAH than in those with ruptured aneurysms. Generally, clipping had a slight upward tendency, while the number of clipped ruptured aneurysms decreased marginally. A significant growing trend was found in the number of unruptured aneurysms and endovascular procedures over the 4-year study period. A marked shift in the therapy allocation from surgical clipping to endovascular coiling was noted for both ruptured and unruptured aneurysms after publication of the results of the International Subarachnoid Aneurysm Trial (ISAT) in 2002 [17]. There was a prominent change in the number of procedures performed prior to and after the ISAT study; namely, there was an increase in endovascular procedures in the post-ISAT period ( $3 \%$ vs. $17 \%$ ), a decrease in surgical procedures ( $31 \%$ vs. $23 \%$ ), and a nonsignificant increase in proportion of patients who get any treatment (surgical or endovascular) [20]. A European study from the United Kingdom reported that the proportion of patients undergoing surgical treatment decreased from $51 \%$ to $31 \%$ while endovascular treatment of aneurysms increased from $35 \%$ to $68 \%$ since publication of ISAT results [8]. Based on US data, endovascular approaches increased in utilization from 11 to $43 \%$ of unruptured and 5 to $31 \%$ ruptured IAs between 1998-2003 [1]. The proportion of patients treated
Fig. 2 Column graph bar presenting number of aneurysms treated by clipping and endovascular therapy in 2009-2012

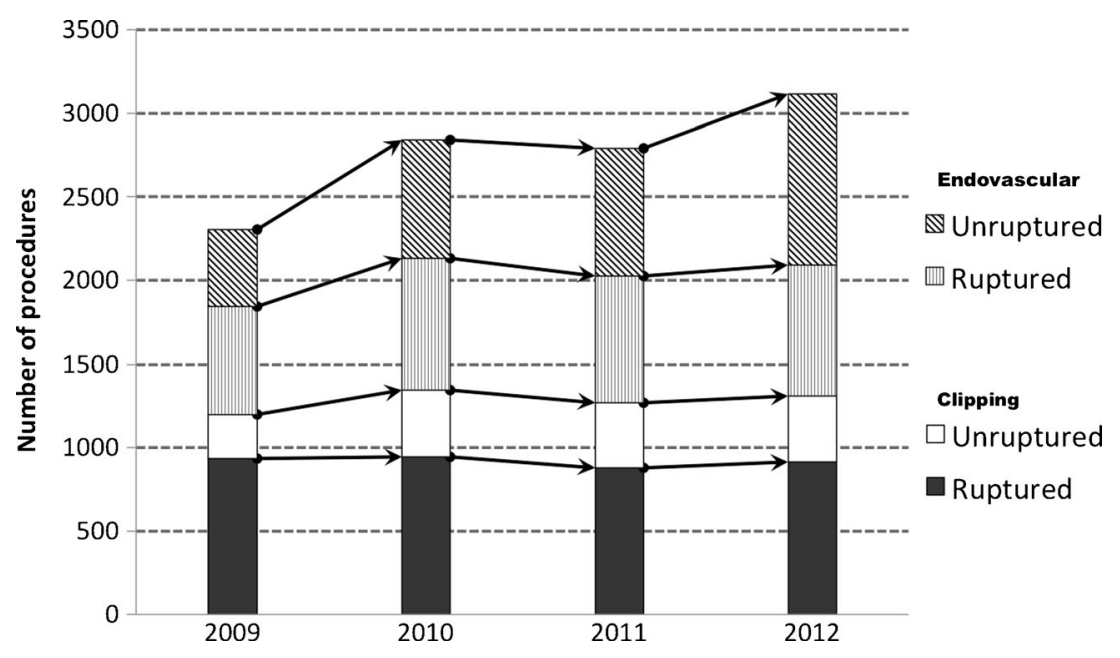


Table 3 Annual comparison of the selected factors in clipping and endovascular groups

\begin{tabular}{|c|c|c|c|c|c|c|c|c|}
\hline & \multicolumn{2}{|l|}{2009} & \multicolumn{2}{|l|}{2010} & \multicolumn{2}{|l|}{2011} & \multicolumn{2}{|l|}{2012} \\
\hline & $\begin{array}{l}\text { Clipping } \\
\mathrm{n}=1,199\end{array}$ & $\begin{array}{l}\text { Endovascular } \\
\mathrm{n}=1,103\end{array}$ & $\begin{array}{l}\text { Clipping } \\
\mathrm{n}=1,345\end{array}$ & $\begin{array}{l}\text { Endovascular } \\
\mathrm{n}=1,495\end{array}$ & $\begin{array}{l}\text { Clipping } \\
\mathrm{n}=1,269\end{array}$ & $\begin{array}{l}\text { Endovascular } \\
\mathrm{n}=1,525\end{array}$ & $\begin{array}{l}\text { Clipping } \\
\mathrm{n}=1,312\end{array}$ & $\begin{array}{l}\text { Endovascular } \\
\mathrm{n}=1,803\end{array}$ \\
\hline In-hospital mortality & $92(7.7 \%)$ & $67(6.1 \%)$ & $111(8.3 \%)$ & $94(6.3)$ & $91(7.2 \%)$ & $102(6.7 \%)$ & $96(7.3 \%)$ & $133(7.4 \%)$ \\
\hline Age (years) & $55.3 \pm 3.3$ & $52.4 \pm 4.1$ & $54.6 \pm 2.9$ & $49.1 \pm 3.1$ & $53.1 \pm 4.6$ & $52.8 \pm 4.6$ & $56.8 \pm 3.7$ & $51 \pm 4.8$ \\
\hline No. of women & $647(54 \%)$ & $699(63.4 \%)$ & $732(54.4 \%)$ & $963(64.4 \%)$ & $714(56.3 \%)$ & $990(64.9 \%)$ & $746(56.9 \%)$ & $1,175(65.2 \%)$ \\
\hline LOS (days) & $11.3 \pm 1.1$ & $7.2 \pm 0.9$ & $12.8 \pm 0.9$ & $7.1 \pm 0.8$ & $11.5 \pm 1.2$ & $6.7 \pm 0.6$ & $12.1 \pm 0,8$ & $5.5 \pm 0.7$ \\
\hline ICA (n)\# & $381(31.8 \%)$ & $424(38.4 \%)$ & $457(34 \%)$ & $531(35.5 \%)$ & $412(32.5 \%)$ & $526(34.5 \%)$ & $425(32.4 \%)$ & $611(33.9 \%)$ \\
\hline MCA (n) \# & $372(31 \%)$ & $139(12.6 \%)$ & $405(30.1 \%)$ & $172(11.5 \%)$ & $370(29.2 \%)$ & $191(12.5 \%)$ & $387(29.5 \%)$ & $224(12.4 \%)$ \\
\hline $\mathrm{ACA}(\mathrm{n}) \#$ & $366(30.5 \%)$ & $427(38.7 \%)$ & $417(31 \%)$ & $449(30 \%)$ & $389(30.7 \%)$ & $475(31.1 \%)$ & $394(30 \%)$ & $552(30.6 \%)$ \\
\hline
\end{tabular}

LOS - length of stay

\# territory of internal carotid artery (ICA); middle cerebral artery (MCA); anterior cerebral artery (ACA)

endovascularly increased from $49 \%$ before to $87 \%$ prior and after the ISAT [15]; in France over $85 \%$ of patients with aneurysms underwent coil embolization event before the ISAT trial began [5].
Fig. 3 Forest plots comparing selective factors between endovascular treament and clipping in unruptured (a) and ruptured aneurysms (b) a

\begin{tabular}{|c|c|}
\hline Odds ratio & \\
\hline 1,$669 ; 1,552$ to 1,794 & Therapy allocation \\
\hline 0,$824 ; 0,737$ to 0,921 & Age \\
\hline 1,$285 ; 1,159$ to 1,424 & No of females \\
\hline 0,$797 ; 0,683$ to 0,930 & In-hopital mortality \\
\hline $0.579: 0.489$ to 0.685 & Posterior circulation \\
\hline 0,$953 ; 0,853$ to 1,065 & LOS \\
\hline 0,$662 ; 0,595$ to 0,735 & $I C A$ \\
\hline 3,$19 ; 2,748$ to 3,703 & $M C A$ \\
\hline 1,$554 ; 1,383$ to 1,746 & $A C A$ \\
\hline
\end{tabular}

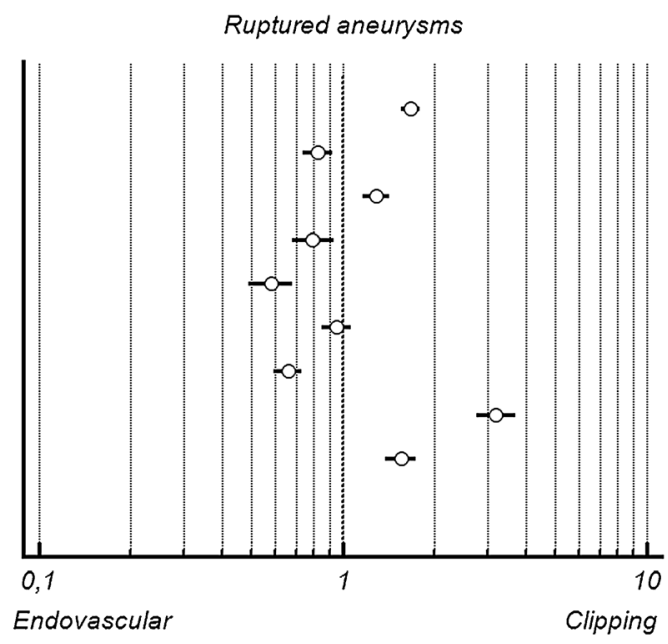

Odds ratio

b

Odds ratio $95 \% \mathrm{Cl}$

0,$281 ; 0,259$ to 0,305

0,$923 ; 0,826$ to 1,031

0,$455 ; 0,399$ to 0,519

1,$093 ; 0,645$ to 1,854

0,118 ; 0,091 to 0,151

2,$013 ; 1,814$ to 2,235

1,101; 0,971 to 1,248

3,$612 ; 3,148$ to 4,146

0,$865 ; 0,762$ to 0,983

Therapy allocation
Age
No of females
In-hopital mortality
Posterior circulation
$L O S$
$I C A$
$M C A$
$A C A$

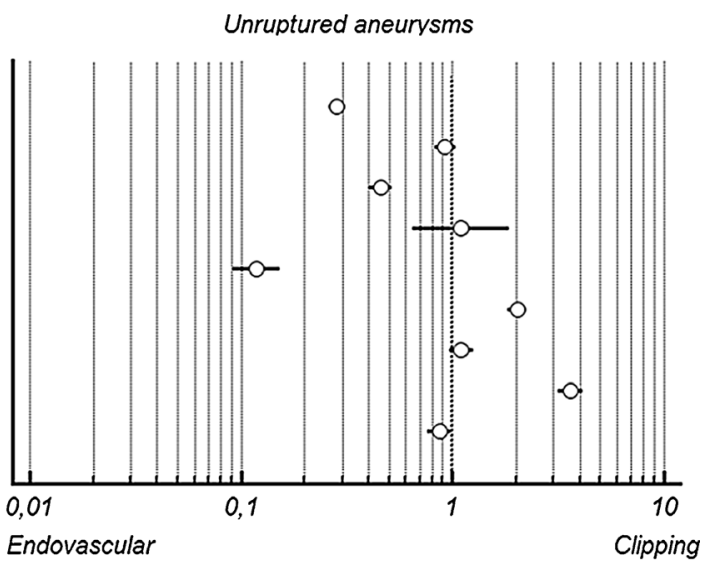

Odds ratio 
Table 4 Number of aneurysm treatment procedures in sixteen Polish regions in clipping and endovascular groups

\begin{tabular}{|c|c|c|c|c|c|c|c|c|c|c|}
\hline \multirow[b]{2}{*}{ Region/Voivodship } & \multicolumn{2}{|l|}{2009} & \multicolumn{2}{|l|}{2010} & \multicolumn{2}{|l|}{2011} & \multicolumn{2}{|l|}{2012} & \multicolumn{2}{|c|}{$\begin{array}{l}\text { Compound annual growth } \\
\text { rate (\%); 2009-2012 }\end{array}$} \\
\hline & clipping & endovascular & clipping & endovascular & clipping & endovascular & clipping & endovascular & clipping & endovascular \\
\hline Lower Silesian & 38 & 145 & 73 & 157 & 63 & 215 & 41 & 242 & $2 \%$ & $14 \%$ \\
\hline Kuyavian-Pomeranian & 54 & 114 & 96 & 116 & 104 & 119 & 56 & 149 & $1 \%$ & $6.9 \%$ \\
\hline Lublin Region & 119 & 62 & 155 & 148 & 135 & 160 & 129 & 196 & $2 \%$ & $33.3 \%$ \\
\hline Lubusz Region & 38 & 0 & 40 & 0 & 45 & 0 & 43 & 0 & $3 \%$ & $0 \%$ \\
\hline Lodz Region & 73 & 55 & 91 & 84 & 85 & 48 & 77 & 65 & $1 \%$ & $4.3 \%$ \\
\hline Lesser Poland & 133 & 47 & 155 & 78 & 140 & 82 & 126 & 95 & $-1 \%$ & $19.2 \%$ \\
\hline Mazovia & 312 & 367 & 416 & 397 & 459 & 457 & 493 & 489 & $12 \%$ & $7 \%$ \\
\hline Opole Region & 34 & 8 & 21 & 9 & 21 & 7 & 24 & 6 & $-8 \%$ & $-6.9 \%$ \\
\hline Podkarpacie Region & 18 & 0 & 19 & 50 & 22 & 93 & 23 & 42 & $6 \%$ & $0.0 \%$ \\
\hline Podlasie Region & 23 & 58 & 27 & 50 & 25 & 83 & 33 & 41 & $9 \%$ & $-8 \%$ \\
\hline Pomeranian & 68 & 0 & 87 & 4 & 105 & 35 & 105 & 48 & $11 \%$ & $0.0 \%$ \\
\hline Silesian & 113 & 141 & 160 & 170 & 135 & 236 & 151 & 221 & $8 \%$ & $11.9 \%$ \\
\hline Swietokrzyski Region & 35 & 22 & 33 & 52 & 26 & 56 & 22 & 80 & $-11 \%$ & $38 \%$ \\
\hline Warmian-Mazurian & 35 & 0 & 28 & 10 & 34 & 31 & 33 & 15 & $-1 \%$ & $0.0 \%$ \\
\hline Greater Poland & 34 & 221 & 66 & 378 & 58 & 477 & 58 & 557 & $14 \%$ & $26.0 \%$ \\
\hline West Pomeranian & 84 & 66 & 88 & 78 & 100 & 86 & 92 & 122 & $2 \%$ & $17 \%$ \\
\hline
\end{tabular}

The legitimate factors related to the shift in treatment selection include subsequent technologic advances such as more prevalent usage of stent-assistant coiling, increased availability of endovascular procedures. There have also been substantial improvements in endovascular technology, such as bioactive coils, expandable coils, and complex-shaped coils during the same period, which may account for some of observed increase in utilization $[7,16]$.

Fig. 4 Administrative map of Poland showing the annual number of overall aneurysm treated in 2009-2012 in 16 regions. Compound annual growth rates (\%) between 2009 and 2012 are presented in parentheses

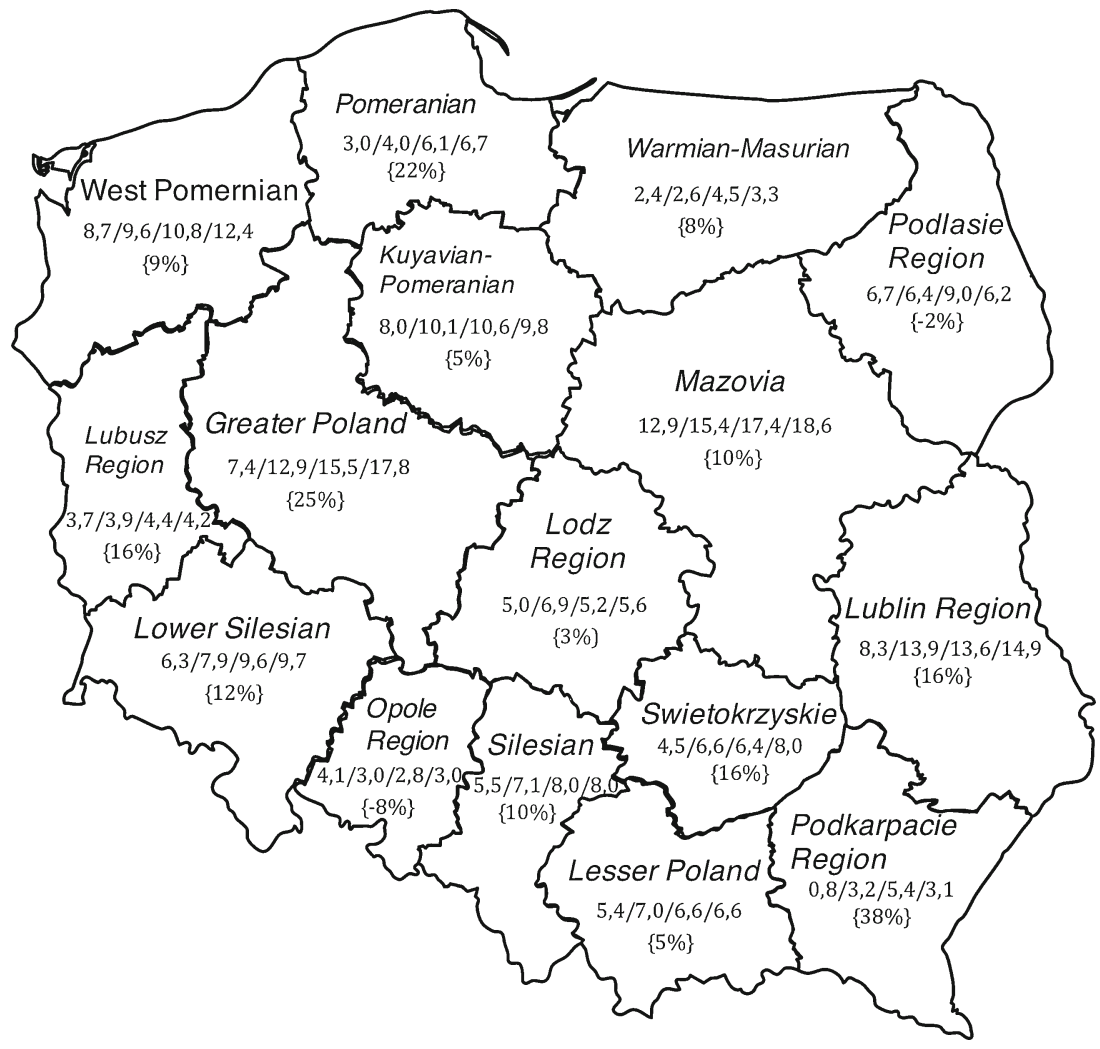


Piotin et al. concluded that stent-assisted coiling reduced the recurrence rate, but in exchange, a higher rate of morbidity and mortality has appeared. The overall rate of permanent, procedure-related morbidity and mortality was $12 \%$ for the stent-treated cohort compared with $5 \%$ in the non-stenttreated group [18].

Based on the data from this study, clipping was three times more often utilized than coiling for treatment of MCA IAs. There is a disparity across Europe in the treatment selection for MCA IAs. Northern European countries strongly favour coiling in comparison with the rest of Europe, where clipping is the treatment of choice [3]. The rationale is based on excellent results in surgical series with MCA IAs [21, 25]. The main arguments against endovascular treatment include broad necks, branches frequently originate from the base or side wall of the aneurysm, increasing the risk of branch occlusion with coiling, large or giant size, intraluminal thrombus, fusiform or complex morphology [21]. However, the recommendations for MCA IAs are based not on highpowered studies but only on personal experience. Endovascular treatment may thus be proposed as an alternative to surgical clipping with very promising results at this location $[2,12,19]$. Contrary to MCA IAs, those in posterior circulation were over three times more likely to be coiled than clipped. This difference was even more scattered for unruptured IAs favouring endovascular treatment 8.5 times more often than the surgery. The tendency to coil posterior circulation IAs is mostly associated with the more complex and challenging operative approach and, what is more, extensive experience in neurovascular surgery. The dominance of endovascular treatment in the field of vertebrobasilar aneurysms is obvious across the whole of Europe [3]. ISAT's impact in the US has been weaker, but in a series of 100 consecutive patients that had been treated by one neurosurgeon using either surgical clip application or endovascular coil embolization, none of the 17 posterior circulation aneurysms were clipped [13]. Literature review by Sanai et al. found comparable overall outcomes after clipping $(n=2,377)$ or coiling $(\mathrm{n}=857)$; however, endovascular therapy was associated with higher incomplete aneurysm occlusion $(8.2 \%$ vs. $4 \%$ ), recurrence ( $9.9 \%$ vs. $0 \%$ ), rehemorrhage (5\% vs. $0.2 \%$ ) [22]. In the BRAT study, the outcomes of posterior circulation aneurysms were significantly better in the coil group than in the clip group after the first year of follow-up, and this difference persisted after 3 years of follow-up [23]. However, the perception that endovascular therapy is superior to microsurgical clipping for posterior circulation aneurysms is not based on clear evidence.

This study showed that the annual in-hospital mortality was 1.2 times higher in the clipping group (7.6\%) compared to endovascular treatment $(6.7 \%)$. Endovascular coiling was associated with slightly lower in-hospital mortality for patients with unruptured factors, but higher in SAH group in comparison to clipping. Including all studied IAs, surgical clipping had two times longer mean length of hospitalization than the endovascular treatment $(11.9 \pm 0.7$ vs. $6.6 \pm 0.8$ days $)$. Similar finding was noted in unruptured group $(\mathrm{OR}=2.013)$, whereas after SAH LOS was almost equal in both methods of treatment. Data from the Nationwide Inpatient Sample showed that in-hospital mortality decreased from $9.7 \%$ to $6.9 \%$ in the clipped group and from $7.2 \%$ to $6.7 \%$ in the endovascular group over a decade (1993-2003) [1]. Cowan et al. reported that in unruptured IAs endovascularly treated patients had a shorter LOS ( 2 compared with 5 days) but the LOS in SAH patients was shorter in clipped aneurysms (15 compared with 17 days median) [6]. Similar data were shown by Hoh et al. in the 2-year retrospective study of 545 patients [10]. The longer LOS and higher in hospital mortality after sole endovascular procedures may result from the lack of decompressive craniectomy in severe brain edema with mass effect, brainstem compression and persistent intracerebral hematoma in some cases after SAH [7].

However, early after endovascular therapy had been introduced, it was used mainly in older patients, poor grade subarachnoid hemorrhage, and large or giant aneurysms. Although the proportions have recently changed toward being more balanced, a slight skew to shift more severe cases to coiling still exists [7].

There is a high disparity across the geographical regions in Poland in the number of procedures. This is consistent with a previous study referring to the overall number of neurosurgical procedures, in which a significant regional scatter of neurosurgical operations was found [24]. Regional unequal ratio in the number of clipped to coiled IAs reflects the uneven development of the endovascular therapy, especially when in some regions a total lack or only a few endovascular procedures could be found. Bradac et al. in the European internet aneurysm study found that Eastern European countries use endovascular coiling much less than the rest of Europe [3]. However, the global number of clipped and coiled IAs was comparable in our study, with the predominance of endovascular treatment $(5,926$ vs. 5,125$)$ over the entire period.

\section{Conclusions}

The trend analysis revealed an increase in overall number of aneurysms treated between 2009-2012. A significant upward trend of endovascular procedures was found, whereas the number of clipped aneurysms remained relatively steady over the study period. Middle cerebral artery aneurysms were predominantly allocated to surgical clipping, whereas posterior circulation aneurysms were mostly treated by endovascular therapy in both unruptured and ruptured groups. The length of hospital stay was almost equal after $\mathrm{SAH}$, but in unruptured 
aneurysms the hospital stay was two times longer after clipping.

A high disparity in the number of procedures across the geographical regions in Poland was pronounced; the difference was especially noticeable in endovascular therapy.

\section{Conflicts of interest None.}

Open AccessThis article is distributed under the terms of the Creative Commons Attribution License which permits any use, distribution, and reproduction in any medium, provided the original author(s) and the source are credited.

\section{References}

1. Andaluz N, Zuccarello M (2008) Recent trends in the treatment of cerebral aneurysms: analysis of a nationwide inpatient database. $\mathrm{J}$ Neurosurg 108:1163-1169

2. Bracard S, Abdel-Kerim A, Thuillier L, Klein O, Anxionnat R, Finitsis S, Lebedinsky A, de Freitas CM, Pinheiro N, de Andrade GC, Picard L (2010) Endovascular coil occlusion of 152 middle cerebral artery aneurysms: initial and midterm angiographic and clinical results. J Neurosurg 112:703-708

3. Bradac O, Hide S, Mendelow DA, Benes V (2012) Aneurysm treatment in Europe 2010: an internet survey. Acta Neurochir 154:971-978

4. Brinjikji W, Rabinstein AA, Nasr DM, Lanzino G, Kallmes DF, Cloft HJ (2011) Better outcomes with treatment by coiling relative to clipping of unruptured intracranial aneurysms in the United States, 2001-2008. AJNR Am J Neuroradiol 32:1071-1075

5. Cognard C, Weill A, Castaings L, Rey A, Moret J (1998) Intracranial berry aneurysms: angiographic and clinical results after endovascular treatment. Radiology 206:499-510

6. Cowan JA Jr, Ziewacz J, Dimick JB, Upchurch GR Jr, Thompson BG (2007) Use of endovascular coil embolization and surgical clip occlusion for cerebral artery aneurysms. J Neurosurg 107:530-535

7. Darsaut TE, Kotowski M, Raymond J (2012) How to choose clipping versus coiling in treating intracranial aneurysms. Neuro-Chirurgie 58: $61-75$

8. Gnanalingham KK, Apostolopoulos V, Barazi S, O'Neill K (2006) The impact of the international subarachnoid aneurysm trial (ISAT) on the management of aneurysmal subarachnoid haemorrhage in a neurosurgical unit in the UK. Clin Neurol Neurosurg 108:117-123

9. Guglielmi G, Vinuela F, Duckwiler G, Dion J, Lylyk P, Berenstein A, Strother C, Graves V, Halbach V, Nichols D, Hopkins N, Ferguson R, Sepetka I (1992) Endovascular treatment of posterior circulation aneurysms by electrothrombosis using electrically detachable coils. J Neurosurg 77:515-524

10. Hoh BL, Chi YY, Dermott MA, Lipori PJ, Lewis SB (2009) The effect of coiling versus clipping of ruptured and unruptured cerebral aneurysms on length of stay, hospital cost, hospital reimbursement, and surgeon reimbursement at the university of Florida. Neurosurgery 64:614-619, discussion 619-621
11. Hughey AB, Lesniak MS, Ansari SA, Roth S (2010) What will anesthesiologists be anesthetizing? Trends in neurosurgical procedure usage. Anesth Analg 110:1686-1697

12. Iijima A, Piotin M, Mounayer C, Spelle L, Weill A, Moret J (2005) Endovascular treatment with coils of 149 middle cerebral artery berry aneurysms. Radiology 237:611-619

13. Lanzino G, Fraser K, Kanaan Y, Wagenbach A (2006) Treatment of ruptured intracranial aneurysms since the International Subarachnoid Aneurysm Trial: practice utilizing clip ligation and coil embolization as individual or complementary therapies. J Neurosurg 104:344-349

14. Lin N, Cahill KS, Frerichs KU, Friedlander RM, Claus EB (2012) Treatment of ruptured and unruptured cerebral aneurysms in the USA: a paradigm shift. J Neurointerv Surg 4:182-189

15. Lindsay KW (2003) The impact of the International Subarachnoid Aneurysm Treatment Trial (ISAT) on neurosurgical practice. Acta Neurochir 145:97-99

16. Linfante I, Wakhloo AK (2007) Brain aneurysms and arteriovenous malformations: advancements and emerging treatments in endovascular embolization. Stroke 38:1411-1417

17. Molyneux A, Kerr R, Stratton I, Sandercock P, Clarke M, Shrimpton J, Holman R, International Subarachnoid Aneurysm Trial Collaborative G (2002) International Subarachnoid Aneurysm Trial (ISAT) of neurosurgical clipping versus endovascular coiling in 2143 patients with ruptured intracranial aneurysms: a randomised trial. Lancet 360:1267-1274

18. Piotin M, Blanc R, Spelle L, Mounayer C, Piantino R, Schmidt PJ, Moret J (2010) Stent-assisted coiling of intracranial aneurysms: clinical and angiographic results in 216 consecutive aneurysms. Stroke J Cereb Circ 41:110-115

19. Quadros RS, Gallas S, Noudel R, Rousseaux P, Pierot L (2007) Endovascular treatment of middle cerebral artery aneurysms as first option: a single center experience of 92 aneurysms. AJNR Am J Neuroradiol 28:1567-1572

20. Qureshi AI, Vazquez G, Tariq N, Suri MF, Lakshminarayan K, Lanzino G (2011) Impact of International Subarachnoid Aneurysm Trial results on treatment of ruptured intracranial aneurysms in the United States. Clinical article. J Neurosurg 114:834-841

21. Rodriguez-Hernandez A, Sughrue ME, Akhavan S, HabdankKolaczkowski J, Lawton MT (2013) Current management of middle cerebral artery aneurysms: surgical results with a "clip first" policy. Neurosurgery 72:415-427

22. Sanai N, Tarapore P, Lee AC, Lawton MT (2008) The current role of microsurgery for posterior circulation aneurysms: a selective approach in the endovascular era. Neurosurgery 62:1236-1249, discussion 1249-1253

23. Spetzler RF, McDougall CG, Albuquerque FC, Zabramski JM, Hills NK, Partovi S, Nakaji P, Wallace RC (2013) The Barrow Ruptured Aneurysm Trial: 3-year results. J Neurosurg 119: $146-157$

24. Tykocki T, Mandat T, Bonicki W, Barszcz S, Michalik R, Kunicki J, Ozieblo A, Kostkiewicz B, Nauman P (2012) Statistical analysis of the intracranial procedures in Poland in 2008-2009. Neurol Neurochir Pol 46:326-332

25. van Dijk JM, Groen RJ, Ter Laan M, Jeltema JR, Mooij JJ, Metzemaekers JD (2011) Surgical clipping as the preferred treatment for aneurysms of the middle cerebral artery. Acta Neurochir 153:21112117 